\title{
Reviving the Individual in Socio-technical Systems Thinking
}

\author{
Lars Taxén ${ }^{*}$ \\ Department of Computer and Information Science, \\ The Institute of Technology, Linköping University, Linkoping Sweden \\ lars.taxen@gmail.com
}

\begin{abstract}
Socio-technical Systems theory sees an organizational work system as comprised of two distinct subsystems - a technical and a social one - that influence each other. Together, these subsystems determine the performance of the work system. Alternative socio-technical trends, such as sociomateriality, understand the social and material as non-existent before they are related. A problematic feature of both approaches is the downplaying of the individual, which is either subsumed under the social or only cursorily treated. To this end, an alternative approach for socio-technical systems thinking is proposed, based on the premise that the individual and social are distinct phenomena, however dialectically constituting each other in everyday activities. We illustrate the central idea of the approach with an example from the telecom industry. Further, we discuss theoretical and practical implications of the approach to be elaborated in future research. In conclusion, we provide a theoretical foundation for advancing socio-technical systems thinking in which the individual is on par with the social and the technical.
\end{abstract}

Keywords: Socio-technical Systems Theory, Individual, Dialectics, Neurobiological Abilities, Activity Modalities.

\section{Introduction}

The aim of socio-technical systems theory is to elucidate the relation between the human, social, and technological aspects of work systems. In mainstream theorizing, this relation is conceived of as linking two relata - a technical subsystem and a social subsystem - which should be jointly designed and optimized to achieve optimal performance [1]. Another theory addressing the same core problem is the influential sociomaterial line of research [2], which focuses on the relation between the social and the material: "People and things only exist in relation to each other" [3, p. 455].

As evident from their labels, both socio-technical systems theory and sociomateriality foreground the 'social' before the 'individual'. Although "the socio-technical approach is innately human centered" [4, p. 495], the difference between 'human' and 'social' is rarely

\footnotetext{
* Corresponding author

(C) 2020 Lars Taxén. This is an open access article licensed under the Creative Commons Attribution License (http://creativecommons.org/licenses/by/4.0).
}

Reference L. Taxén, "Reviving the Individual in Sociotechnical Systems Thinking," Complex Systems Informatics and Modeling Quarterly, CSIMQ, no. 22, pp. 39-48, 2020. Available: https://doi.org/10.7250/csimq.2020-22.03

Additional information. Author's ORCID iD: L. Taxén - https://orcid.org/0000-0002-9317-9120. PII S225599222000128X. Received: 31 October 2019. Accepted: 12 February 2020. Available online: 30 April 2020. 
problemized. If attended at all, the individual is usually conflated with or subsumed under the social. According to Baxter and Sommerville, socio-technical design methods are rarely used, which may partly be due to "issues of individual interaction with technical systems" [5, p. 4]. More outspoken, Kant claims that "The individual as a fundamentally social construct remains underemphasized" [6, p. 309] in socio-technical systems theory.

The conspicuous inattention to the individual in theorizing the social is indeed strange, considering that the individual is the acting subject in every human society, regardless of when and where in history. The social and technical come into existence only through individual actions. Likewise, a human infant cannot survive on its own; it is fundamentally dependent on a social environment to become an individual. To this end, the purpose of this article is to make an inquiry into socio-technical theorizing, based on the core tenet that the individual and social mutually constitute each other - a dialectical approach. ${ }^{\dagger}$

The line of argument is as follows. First, we introduce the communal infrastructure, which conceptualizes prerequisites for any action: "There is always something that exists first as a given" [8, p. 5]. In this infrastructure, individuals are represented as biomechanical factors, and the social as communal factors. Next, we outline communalization as the dialectical process by which biomechanical and communal factors, i.e. the individual and the social, co-evolve. Together, this line of thinking coalesces into a theoretical framework for conceptualizing the relation between individual, social and material/technological. Further, we discuss theoretical and practical implications of the approach to be elaborated in future research. In conclusion, we provide a theoretical foundation for advancing socio-technical systems thinking in which the individual is on par with the social and the technical.

\section{The Communal Infrastructure}

Our point of departure is that brains "evolved to control the activities of bodies in the world... the mind consists of structures that operate on the world via their role in determining action" [9, p. 527]. Such structures emanate from the innate, neurobiological predispositions for action brought about by the phylogenetic evolution of humankind. Thus, every healthy human being meets the world endowed with a certain species-specific, mental and physical 'infrastructure'. We all "share anatomy and common biomechanical and task constraints... We all discover walking rather than hopping" [10].

However, it is only in a social environment that these latent predispositions can develop. Biomechanical predispositions do not translate into abilities unless there is the opportunity to exercise them. For instance, "Doubtless many contemporaries of Julius Caesar had the biomechanical capacity to become pianists; but were never able to develop the corresponding biomechanical ability because the pianoforte had not yet been invented" [11, p. 29].

During the cultural-historical evolution of humankind, social actions are manifested as diverse communities, loosely defined as groups of people that bond together by a shared interest, a shared identity and a shared set of norms [12]. Communities "develop, change, and remain constant as a result of individual actions, and yet the results of this process, the artifacts and ideational contents it creates, constitute an apparently constant or resistant framework for its inhabitants... and as such it will constitute, for each new individual born into it, a pre-established environment to be discovered and structured" [13, p. 31, original emphasis].

The activity modalities. A central issue in this line of reasoning is how to conceptualize the biomechanical factors enabling action in different situations. Such factors need to be compliant with extant neuroscientific findings to be trustworthy grounded. Acknowledging this, we propound that the individual needs to mentally discern at least the following aspects of a situation:

\footnotetext{
Dialectics has a long philosophical tradition from Aristoteles, Hegel, Marx and others [7].
} 
- Acting implies attending 'some-thing', an object. This entails an objectivating neurobiological capacity to focus onto the object. The nature of this object "is constituted by the meaning it has for the person or persons for whom it is an object... this meaning is not intrinsic to the object but arises from how the person is initially prepared to act toward it" [14, pp. 68-69].

- Focusing attention onto some-thing implies that other things will be unattended. This entails a contextualizing capacity to project in the mind a context of relevance around the object - a "horizon of meaning" [15, p. 383].

- The spatial structure of the situation needs to be grasped, which entails a spatializing neurobiological capacity. Spatial factors signify "the way we shape the very world that constrains and guides our behavior" [16, p. 31].

- A temporalizing neurobiological capacity [17] is requisite for anticipating the temporal structure of the situation; the sequence of actions towards the object, leading to the fulfillment of the need that motivates the action in the first place.

- The normative structure of the situation, manifested as habits, rules, conventions, traditions, etc., needs to be adhered to, which entails a habitualizing neurobiological capacity: "People's thoughts, feelings, and predispositions for action are inherently dynamic, displaying constant change due to internal mechanisms and external forces, but over time the flow of thought and action converges on a narrow range of states - a fixed-point attractor - that provides cognitive, affective, and behavioral stability" [18, p. 351].

- When acting in a situation is ended, attention is directed to other situations. A transition from one situation to another entails a transiting neurobiological capacity to refocus attention in which "the cortical system rapidly breaks functional couplings within one set of areas and establishes new couplings within another set" [19, p. 4].

Hence, we posit that the phylogenetic evolution of humankind has brought about the biomechanical factors objectivating, contextualizing, spatializing, temporalizing, habitualizing, and transiting as requisite neurobiological capacities for acting in the world. These develop into specific neurobiological abilities depending on situations the individual encounters. However, regardless of the endemics of a particular situation, action always necessitates the mental capacity to confer signhood onto communal factors signifying contextualized objects, spaces, times, and norms. Transitional factors enable the transition from one community to another, in which other objects, spaces, times, and norms are contextualized. Consequently, the meaning we assign to communal factors will reflect our neurobiological predispositions (cf. Kant's 'a priori' categories [20]). The neural is reflected in the social; we see the world as filtered through our evolutionary inherited neurobiological capacities for surviving in it.

To further articulate this dialectic, we introduce the concepts of activity modalities [21], [22]. This means that we conceive of the dialectical relation between the individual and the social as constituted by the six dimensions of the activity modalities. These make up a totality in the sense that action is thwarted if anyone is inhibited, for instance, by a lesion in some part of the brain. However, even if all modalities are necessary for acting, this does not mean that they are sufficient. Other factors, such as intentions, trust, emotions, power structures, and more, are indeed relevant for carrying out actions. The implication for social sciences is that "the cognitive, normative, and regulative structures and activities that provide stability and meaning to social behavior" [23, p. 33] will be structured according to the activity modalities. Every community will contain communal factors that can be recognized as objects, contexts, spaces, times, norms, and transitions.

Importantly, communal factors have a double character. On the one hand, they are unique for each individual. The meaning assigned to them always differs between individuals, simply because biomechanical factors are idiosyncratic. On the other hand, communal factors are shared in the sense that they are community-relevant phenomena, which can be sensed by actors in that community. These phenomena always have a material basis. So, for instance, actors in a 
nonliterate society do not have a written language - a writing system. However, they still have a spoken language resulting from clustering of individual biomechanical factors around stabilized, communal utterances. In an English-speaking society, there is no need for a written statement to understand the utterance - a material phenomenon in the form of a sound wave - "there is a cat in the garden".

\section{Communalization}

Communalization is the process by which the communal infrastructure unfolds as a result of individual actions. Archer [24] has articulated this process in terms of a "morphogenetic sequence", which we interpret as follows (Figure 1):

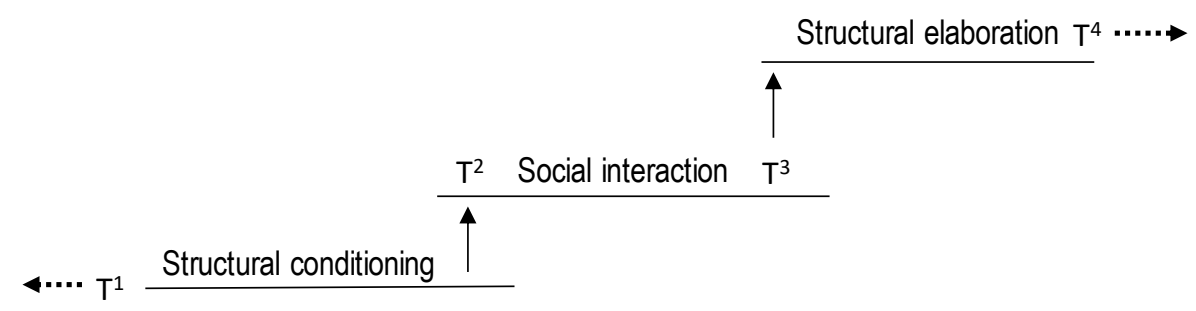

Figure 1. The morphogenetic sequence (based on [24, p. 76])

At $\mathrm{T}^{1}$, existing biomechanical and communal factors provide structural conditions for acting at $\mathrm{T}^{2}$. Social interaction between $\mathrm{T}^{2}$ and $\mathrm{T}^{3}$ is conceived as individual action, constrained and enabled by the current state of biomechanical and communal factors at $\mathrm{T}^{1}$. Action results in structural elaboration, which changes both factors into new structural conditioning for further actions at $\mathrm{T}^{4}$. Thus, we understand the sequence from $\mathrm{T}^{1}$ to $\mathrm{T}^{4}$ as an evolution of the communal infrastructure, ceaselessly providing new conditions for further actions. Thus, communalization has an intrinsic temporal dimension, where changes occur on vastly different timescales, ranging from milliseconds processes in the brain, hundreds of years of communal development, and millions of years of biological evolution.

From an individual perspective the morphogenetic sequence may be understood as follows. The evolution of biomechanical factors has enabled humans to perceive a range of physical sensations emanating from the environment. Such sensations entering through various sensory modalities, are integrated together with motivation and previous experiences retained from memory, into a multi-dimensional, mental construct comprised of the activity modalities - a Gestalt by which a decision of what to do, how to do, and when to do is taken. ${ }^{\S}$ After carrying out the action, the result is evaluated. Depending on the outcome, the cycle is repeated or halted. The entire episode is then retained in memory for acting relevantly in future, similar situations [17].

Communalization thus conceived implies that we attend sensations emanating from the external world that we comprehend as meaningful, and from which we can decide how to best act in any situation we encounter. If I see a red light when driving, I stop. If I perceive the church on my way back home, I know I shall turn right after I passed it. If I hear someone cry "watch out!", I understand that I should avoid something. However, we do not merely observe the environment - we also change it to fulfill our needs. We define grand goals such as putting a man on the moon or defeating an enemy at war, reflecting our objectivating ability. If we previously navigated by observing landmarks in the nature, we now do it by maps or GPS

\footnotetext{
${ }^{\ddagger}$ Importantly, the model in Figure 1 is for analytical purposes. In reality, action is "continuous, cyclical, flow over time: there are no empty spaces where nothing happens, and things do not just begin and end" [25, p. 203].

$\S$ Hence the term 'modalities' as an indication of the transformation of multidimensional, inward-afferent space into an equally multidimensional, efferent-action space.
} 
systems reflecting our spatializing and temporalizing abilities. We write laws and establish courts reflecting our habitualizing abilities. And so on.

Joint actions. So far, we have been concerned with the dialectics between an individual and social. The next step is to conceptualize how individuals collaborate towards communal goals, fulfilling collective needs. Such joint actions may be defined as "the larger collective form of action constituted by the fitting together of the lines of behavior of the separate participants. ... Joint actions range from a simple collaboration of two individuals to a complex alignment of the acts of huge organizations or institutions" [14, p. 70].

To understand joint action, it is necessary to distinguish between two types of individual actions. When a pianist gives a recital, she performs an autonomous act [26, p. 19]. There is no other musician involved. When the same pianist plays in a piano trio, she also preforms an individual act, but now together with other musicians. Such individual acts, "performed only as parts of joint actions", are called participatory ones [ibid.].

In the dialectical approach outlined here, communal factors are requisite for both types of actions. However, in joint actions, these factors become common identifiers [14, p. 71] towards which participatory actions gravitates. Thus, participatory actions are still uniquely individual, but they may be sufficiently aligned or clustered together for contributing to a common goal.

\section{Illustrating the Practical Relevance of the Approach}

To illustrate the central idea in our framework, we take an example from Ericsson ${ }^{\mathrm{TM}}$, a provider of telecommunication systems worldwide. Around year 2000 Ericsson launched the 3rd generation of mobile systems. The projects developing this system required sophisticated IT support in order to coordinate activities [21], [22]. To signify what information had to be managed in the IT artifact, two different "information models" (A and B) were created at different units at Ericsson (see Figure 2 and Figure 3).

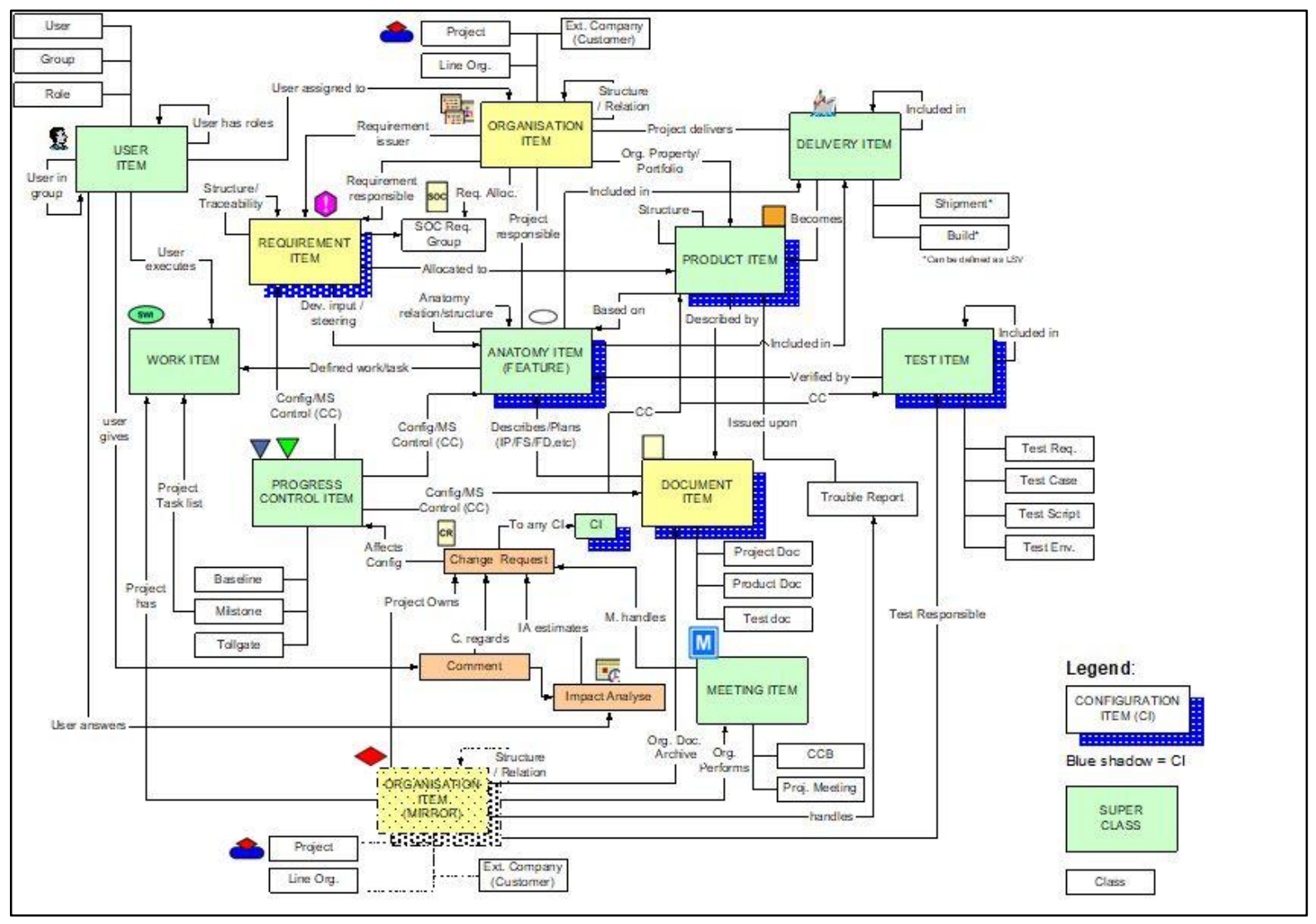

Figure 2. The A model - useful 
These models are so called Entity-relationship models [27], in which each box signifies a community-relevant entity such as 'requirement', 'customer', 'feature', 'product', 'delivery', etc. Lines indicate relationships between entities.

The A model evolved gradually during several years when specialists (project managers, requirement managers, configuration managers, IT specialists, etc.) discussed it, implemented it in the IT artifact and evaluated the results. During this period, the IT artifact and the model were modified several hundred times [21]. In this way, both were communalized into relevant artifacts in the project community. The B model, on the other hand, was developed by a consultant after discussing with key persons. No IT artifact was involved.

On the surface, the models look very similar, and both appear equally valid. In fact, however, there is a profound difference between them. Both are regarded as tangible manifestations of communal factors in the dialectical relation. However, the biological factors - the other relata are intangible, since these are located inside the skull of each individual. The evolution of this relata can only be traced indirectly by attending the historical development of the models. Without understanding the communalization process, it is not possible to see that the A model was instrumental in supporting projects, while the B model was, in fact, useless. Just inspecting the models at a certain point in time is not enough.

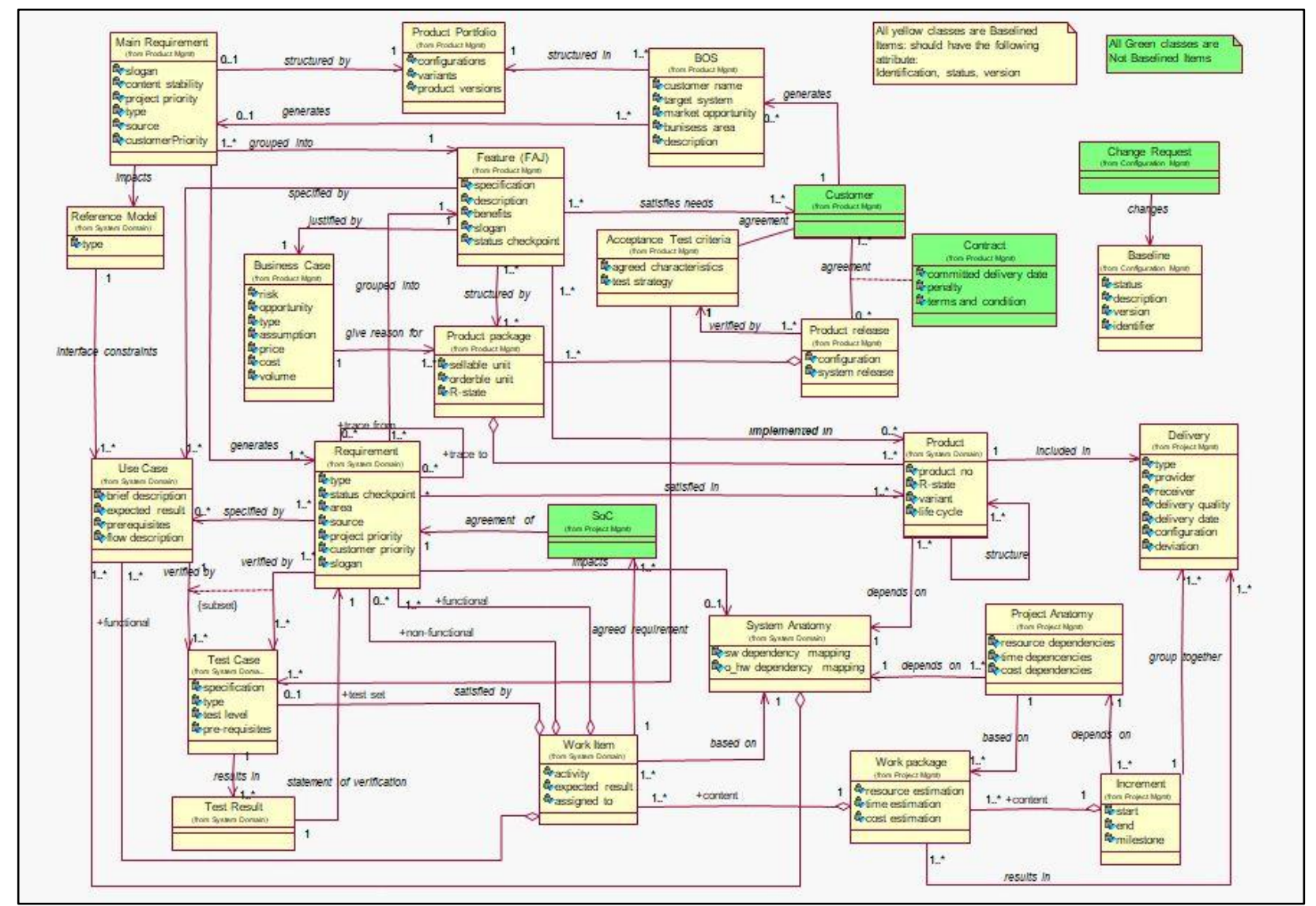

Figure 3. The B model - useless

\section{Implications}

The theoretical framework outlined above makes it possible to see socio-technical systems in new light. Some of the findings are outlined below. These should be seen as indicative directions for avenues to be threaded in future research. 


\subsection{Theoretical Implications}

\section{The social}

In the literature, there is no consensus about what constitutes the social realm [28, p. 12]. Here, this realm is conceived of as a community. This is conceptualized as a communal infrastructure, comprised of individuals in terms of biomechanical factors, and social structures in terms of communal factors. These factors are dialectically related in the sense that neither individuals, nor societies can develop in isolation. Every individual action is constrained and enabled by both factors, and both these change as a result of individual actions.

\section{Materiality}

The material is seen as any physical sensations that we can notice. Such sensations may emanate from 'tangible' things like a hammer that hurts when you drop them on your toe, or from 'intangible', ephemeral things like utterances or fantasies in your mind. In any particular situation, sensations are contextualized into that which is relevance for acting. What matters is how these sensations contribute to informing the individual how to act.

\section{Technology}

Technology is seen as material artifacts designed for particular social purposes, and "relevant only in relation to the people engaging with them" [29, p. 131). In order for any technology to become relevant, it must be communalized, which means that dialectical relationships have been developed between each individual and the technology at hand.

\section{Information}

Information "is constituted - not just interpreted - or symbolically represented and exchanged - but actually constituted as information by the social (cooperatively ordered) aspects of the situated social orders in which it occurs" [30, p. 13, original emphasis]. Thus, the locus of information is the individual neurobiological system, the structuring of which is requisite on the input from the external world: "[Cognitive] systems construed as dynamic systems do not process information transduced from the outside world; they reconfigure themselves in response to an ongoing stream of sensory events" [31, p. 173].

Consequently, information is seen as inherently associated with the evolution of Homo Sapiens, and not restricted to the era starting with the introduction of computerized information systems in the 1960s. Information in this sense has been requisite for the survival of our species ever since the dawn of humankind [cf. 32]. Such a view implies that any external sensation may contribute to the constitution of relevant information, regardless of whether it originates from an IT artifact or some other source. Information is "knowledge for the purpose of taking effective action." [33, p. 475].

\section{Information Systems}

An Information System (IS) is seen as the communalized IT artifact. Consequently, there is no such thing as an separate IS artifact, distinguishable from the IT artifact [34]; only an ongoing, perpetually open-ended communalization of the IT artifact during which the artifact may be changed but never transformed into a different ontological entity. This means that the 'system' in 'information system' is comprised of the individual's neurobiological structure and the IT artifact.

\section{Communication}

Communication is imminent in all accounts for the relation between the social and technical. However, only individuals communicate - not the 'social' or 'technical'. The mainstream view of communication is as a process of 'transmitting' information or 'messages' from one person's mind to another's. This view has been thoroughly criticized [35]. An alternative communication model is Integrational Linguistics [36]. This model provides a fecund point of departure for advancing socio-technical thinking also with respect to communication. 


\subsection{Practical Implications}

A general remark concerning the practical implications of our approach is that it originated in the telecom industry from the author's experiences of coordinating complex system development projects [21], [22], [37]. Thus, practical relevance is an inherent aspect of the approach from its inception. ${ }^{* *}$ Below are a sample of practical implications.

\section{Work system analysis}

According to Alter, a work system is "a system in which human participants and/or machines perform work (processes and activities) using information, technology, and other resources to produce specific products/services for specific internal and/or external customers" [39, p. 75]. In our approach, a work system is differently conceived as a community, structured according to the activity modalities. The dialectics between biomechanical and communal factors implies that the analysis of such a system should proceed from an identification of communal factors, signifying the work system's:

- Object - what is being changed and acted upon by individual actions?

- Context - which is its scope and how does it border to other work systems?

- Spatial structure - which phenomena are relevant in the work system, how are these characterized and related to each other?

- Temporal structure - which sequences of actions are taken towards the object?

- Normative structure - which standards, rules, etc., are adhered to in order to keep the work system stable?

- Transitions to other work systems - how does it collaborate with these?

In line with this, an organization (a work system of its own) is seen as comprised of a set of work systems, each structured according to the activity modalities.

\section{Design of IT artifacts}

An IT artifact is a physical artifact based on technology such as software and hardware [40] which it is intentionally designed to be informative: "This is actually the most important trait and what distinguishes it from many other types of technical artefacts" [40, p. 93, our emphasis]. Someone using the IT artifact should be informed about the state of things in the world in order to act relevantly.

However, you can do something with the artifact besides monitoring it; sending commands, starting a conversation, modifying it, and so on. This means that a 'pure' informative IT artifact is an extreme case. Likewise, artifacts that render mainly external effects, such a hammer or a shotgun, also render informative effects in the sense that someone using it must recognize what it is and how to use it: "A tool is also a mode of language. For it says something, to those who understand it, about the operations of use and their consequences" [41, p. 52]. Accordingly, there is no sharp borderline between IT artifacts and other types of artifacts, only a qualitative difference.

Since we propose that the relation between individuals and the IT-artifact comprises all activity modalities, the IT artifact should be designed in such a way that objects, contexts, spaces, times, norms, and transitions are easily recognized by individuals interacting with the artifact.

\section{Concluding Remarks}

The central idea brought forward in this contribution is that the individual and social are ontologically different entities, however mutually constituting each other. A key point is that each individual "necessarily occupies a different position, acts from that position, and engages in

\footnotetext{
${ }^{* *}$ For further details see [38].
} 
a separate and distinctive act" [14, p. 70]. Stated differently, the individual experience of the world is unique. No two brains are ever the same. This is the unavoidable point of departure, which any theorizing about the relationship between the social and technical must take a stand on. Consequently, the view of socio-technical systems as comprised of two related subsystems a technical and a social one - needs to be rethought from the core. Reviving the individual from its present lurking in the shadows entails a paradigmatic shift of foundational assumptions for socio-technical systems thinking. The social and technical are still valid categories, but these must be viewed from an individual vantage point in future research. This certainly brings more challenging issues to the socio-technical systems arena, but also new, exciting avenues for advancing it.

\section{References}

[1] R. P. Bostrom and J. S. Stephen Heinen, "MIS Problems and Failures: A Socio-Technical Perspective. Part I: The Causes," MIS Quarterly, vol. 1, no. 3, pp. 17-32, 1977. Available: https://doi.org/10.2307/248710

[2] D. Cecez-Kecmanovic, R. D. Galliers, O. Henfridsson, S. Newell, and R. Vidgen, "The Sociomateriality of Information Systems: Current Status, Future Directions," MIS Quarterly, vol. 38, no. 3, pp. 809-830, 2014. Available: https://doi.org/10.25300/MISQ/2014/38:3.3

[3] W. J. Orlikowski and S. V. Scott, "Sociomateriality: Challenging the Separation of Technology, Work and Organization," The Academy of Management Annals, vol. 2, no. 1, pp. 433-474, 2008. Available: https://doi.org/10.1080/19416520802211644

[4] G. H. Walker, N. A. Stanton, P. M. Salmon, and D. J. Jenkins, "A review of sociotechnical systems theory: a classic concept for new command and control paradigms," Theoretical Issues in Ergonomics Science, vol. 9, no. 6, pp. 479-499, 2008. Available: https://doi.org/10.1080/14639220701635470

[5] G. Baxter and I. Sommerville, "Socio-technical systems: from design methods to systems engineering," Interacting with Computers, vol. 23, no. 1, pp. 4-17, 2011. Available: https://doi.org/10.1016/j.intcom.2010.07.003

[6] V. Kant, "Varieties of being "social": Cognitive work analysis, symbolic interactionism, and sociotechnical systems," Human Factors and Ergonomics in Manufacturing \& Service Industries, vol. 28, no. 6, pp. 309-326, 2018. Available: https://doi.org/10.1002/hfm.20764

[7] W. Wong, "Understanding Dialectical Thinking from a Cultural-Historical Perspective," Philosophical Psychology, vol. 19, no. 2, pp. 239-260, 2006. Available: https://doi.org/10.1080/09515080500462420

[8] B. Latour, B. "A cautious Prometheus? A few steps toward a philosophy of design (with special attention to Peter Sloterdijk)," Proceedings of the 2008 Annual International Conference of the Design History Society Falmouth, e-book, Universal Publishers, pp. 2-10, 2009.

[9] N. Love, "Cognition and the language myth," Language Sciences, vol. 26, no. 6, pp. 525-544, 2004. Available: https://doi.org/10.1016/j.langsci.2004.09.003

[10] E. Thelen, "Motor development: A new synthesis," American Psychologist, vol. 50, no. 2, pp. 79-95, 1995. Available: https://doi.org/10.1037/0003-066X.50.2.79

[11] R. Harris, Signs, language, and communication: Integrational and segregational approaches. London: Routledge, 1996.

[12] T. K. Bradshaw, "The Post-Place Community: Contributions to the Debate about the Definition of Community," Community Development, vol. 39, no. 1, pp. 5-16, 2008. Available: https://doi.org/10.1080/15575330809489738

[13] E. Boesch, Symbolic action theory and cultural psychology. Berlin: Springer, 1991. Available: https://doi.org/10.1007/978-3-642-84497-3

[14] H. Blumer, Symbolic interactionism: Perspective and method. Englewood Cliffs, N.J: Prentice-Hall, 1969.

[15] H.-G. Gadamer, Truth and method. London: Sheed and Ward, 1989.

[16] D. Kirsh, "The intelligent use of space," Artificial Intelligence, vol. 73, no. 1-2, pp. 31-68, 1995. Available: https://doi.org/10.1016/0004-3702(94)00017-U

[17] A. Toomela, "Biological Roots of Foresight and Mental Time Travel," Integrative Psychological and Behavioral Science, vol. 44, pp. 97-125, 2010. Available: https://doi.org/10.1007/s12124-010-9120-0 
[18] A. Nowak, R. R. Vallacher, and M. Zochowski, "The emergence of personality: Dynamic foundations of individual variation," Developmental Review, vol. 25, no. 3-4 pp. 351-385, 2005. Available: https://doi.org/10.1016/j.dr.2005.10.004

[19] S. Bressler and J. A. Scott Kelso, "Coordination Dynamics in Cognitive Neuroscience," Frontiers in Neuroscience, vol. 10, article 397, pp. 1-7, 2016. Available: https://doi.org/10.3389/fnins.2016.00397

[20] O. T. Khachouf, S. Poletti, and G. Pagnoni, "The embodied transcendental: a Kantian perspective on neurophenomenology," Frontiers in Human Neuroscience, vol. 7, article 611, pp. 1-15, 2013. Available: https://doi.org/10.3389/fnhum.2013.00611

[21] L. Taxén, A Framework for the Coordination of Complex Systems’ Development. Doctoral thesis. Linköping University, Dep. of Computer \& Information Science, 2003. Available: http://liu.divaportal.org/smash/record.jsf?searchId=1\&pid=diva2:20897

[22] L. Taxén, Using Activity Domain Theory for Managing Complex Systems. Information Science Reference. Hershey PA: Information Science Reference, IGI Global, 2009.

[23] W. R. Scott, Institutions and organizations. Thousand Oaks: Sage, 1995.

[24] M. S. Archer, Realist Social Theory: The Morphogenetic Approach. Cambridge, UK: Cambridge University Press, 1995. Available: https://doi.org/10.1017/CBO9780511557675

[25] S. Fleetwood, "Ontology in Organization and Management Studies: A Critical Realist Perspective," Organization, vol. 12, no. 2, pp. 197-222, 2005. Available: https://doi.org/10.1177/1350508405051188

[26] H. H.Clark, Using language. Cambridge, England: Cambridge University Press, 1996.

[27] P. P. Chen, "The Entity-Relationship Model - Toward a Unified View of Data," ACM Transactions on Database Systems, vol. 1, no. 1, pp. 9-36, 1976. Available: https://doi.org/10.1145/320434.320440

[28] N. R. Hassan, "Editorial: A Brief History of the Material in Sociomateriality," ACM SIGMIS Database: the DATABASE for Advances in Information Systems, vol. 47, no. 4, pp. 10-22, 2016. Available: https://doi.org/10.1145/3025099.3025101

[29] W. J. Orlikowski, "The sociomateriality of organisational life: considering technology in management research," Cambridge Journal of Economics, vol. 34, no. 1, pp. 125-141, 2010. Available: https://doi.org/10.1093/cje/bep058

[30] H. Garfinkel, Toward a Sociological Theory of Information. Boulder, CO: Paradigm Publishers, 2008.

[31] M. D. Lewis, "Bridging emotion theory and neurobiology through dynamic systems modeling," Behavioral and Brain Sciences, vol. 28, pp. 169-194, 2005. Available: https://doi.org/10.1017/S0140525X0500004X

[32] R. T. Watson, “A Personal Perspective on a Conceptual Foundation for Information Systems," Journal of the Association for Information Systems, vol. 15, no. 8, article 1, 2014. Available: https://doi.org/10.17705/1jais.00368

[33] R. O. Mason and I. I. Mitroff, “A Program for Research on Management Information Systems,” Management Science, vol. 19, no. 5, pp. 475-487, 1973. Available: https://doi.org/10.1287/mnsc.19.5.475

[34] A. S. Lee, M. Thomas, and R. L. Baskerville, "Going back to basics in design science: from the information technology artifact to the information systems artifact," Information Systems Journal, vol. 25, no. 1, pp. 5-21, 2015. Available: https://doi.org/10.1111/isj.12054

[35] R. Harris, After epistemology. Gamlingay: Bright Pen, 2009.

[36] R. Harris, Integrationism. Available: http://www.royharrisonline.com/integrationism.html

[37] L. Taxén, “The Dialectical Approach to System Design," Proceedings of Integrated Design and Process Technology, pp. 147-152, 1995.

[38] L. Taxén, Publications, 2019. Available: http://www.ep.liu.se/PubList/Default.aspx?userid=larta94

[39] S. Alter, "Work System Theory: Overview of Core Concepts, Extensions, and Challenges for the Future," Journal of the Association for Information Systems, vol. 14, no. 2, article 1, 2013. Available: https://doi.org/10.17705/1jais.00323

[40] G. Goldkuhl, "The IT artefact: An ensemble of the social and the technical? - A rejoinder," Systems, Signs \& Actions, vol. 7, no. 1, pp. 90-99, 2013.

[41] J. Dewey, 'Logic', The Theory of Enquiry. The Later works of John Dewey. J. A. Boydston (Ed.), The Later Works of John Dewey, vol. 12, 1925-1953: 1938. Southern Illinois University Press, 2008. 